\title{
El tema de la muerte para hablar desde el feminismo a futuras maestras
}

RICARD HUERTA

UNIVERSITAT DE VALÈnCIA

Este artículo forma parte del proyecto "Arteari. Arte y diseño para entornos educativos libres de homofobia y transfobia” referencia UV-INV-AE18-779907 de la Convocatoria de Ayudas para Acciones Especiales de Investigación 2019 del Vicerrectorado de Investigación de la Universitat de València.

\section{Resumen}

El arte contemporáneo es fuente inagotable de recursos para la formación de docentes. Es importante acercar el arte hecho por mujeres a las futuras educadoras para que vinculen la experiencia artística con su propia realidad como mujeres. En la creación artística actual se tratan temas sociales, políticos y culturales que son esenciales para la formación de educadoras. Proponemos estrategias innovadoras para la formación artística del colectivo docente de Educación Primaria. Optamos por temáticas vinculadas a las emociones, las necesidades y la vida cotidiana, como el concepto "la muerte", que permite indagar en las problemáticas actuales y facilita nuevas miradas hacia el arte desde una perspectiva feminista. Abordamos el tema a partir de la obra de Sophie Calle. La metodología es mixta, combinando la Investigación Educativa Basada en las Artes con las "Artografías". Las obras realizadas por el alumnado universitario son expuestas en el Museo de Ciencias Naturales. Destacamos la gran aceptación de los procesos innovadores utilizados así como el reconocimiento de las mujeres artistas.

Palabras clave: Educación Artística, Feminismo, Formación del profesorado, Muerte, Museo. 


\section{Abstract}

Contemporary art is an impressive source of resources for teacher training. It is important to bring the art made by women to future educators, so that they link the art experience with their own reality as women. In contemporary creation, social, political and cultural issues are addressed that are essential for teacher training. We propose innovative strategies for art education in Primary School. We are interested in topics related to emotions, needs and daily life, such as the concept of "death", which allows us to investigate current problems and facilitates new views of art from a feminist perspective. We approach the subject from the work of Sophie Calle. The methodology is mixed, combining Arts-Based Educational Research with Artographies. The works made by university students are exhibited in the Museum of Natural Sciences. We highlight the great acceptance of the innovative processes used as well as the recognition of women artists.

Keywords: Art Education, Feminism, Teacher training, Death, Museum.

\section{Resumo}

A arte contemporânea é uma fonte impressionante de recursos para a formação de professores. É importante aproximar a arte feita por mulheres das futuras educadoras, para que elas vinculem a experiência artística à sua própria realidade como mulheres. Na criação artística atual, são abordadas questões sociais, políticas e culturais essenciais para a formação dos professores. Propomos estratégias inovadoras para a formação artística no Ensino Básico. Estamos interessados em temas relacionados às emoções, necessidades e cotidiano, como o conceito de "morte", que nos permite investigar problemas atuais e possibilita novas visões da arte a partir de uma perspectiva feminista. Abordamos o assunto a partir da obra de Sophie Calle. A metodologia é mista, combinando a Pesquisa Educacional Baseada nas Artes com as ARTografias. Os trabalhos realizados por estudantes universitários estão expostos no Museu de Ciências Naturais. Destacamos a grande aceitação dos processos inovadores utilizados, bem como o reconhecimento das mulheres artistas.

Palavras-chave: Educação Artística, Feminismo, Formação de professores, Morte, Museu. 
“(...) uno es la lista de los amenazados de muerte, una fotocopia, y el otro,

el epitafio de Borges copiado de su puño y letra, salpicado de sangre:

"Ya somos el olvido que seremos"

Héctor Abad Faciolince, El olvido que seremos, p. 245

En mi experiencia como profesor implicado en la formación de maestros he podido comprobar la eficacia del uso del arte contemporáneo en clase. Hablar sobre arte actual hecho por mujeres permite acercar al alumnado a la creación artística y la educación en artes desde una perspectiva muy cercana a sus intereses (Hamlin y Fusaro, 2018). El arte está presente tanto en las galerías y museos como en las acciones que los artistas contemporáneos realizan en el espacio urbano y en los entornos informales en colaboración con las comunidades. Las nuevas emergencias del arte nos permiten tratar cuestiones cercanas al alumnado implicando las corrientes feministas (Alonso-Sanz, 2019a).

Desarrollamos proyectos desde temáticas atractivas e innovadoras a partir de conceptos como el miedo, el cuerpo, la memoria, o la muerte. Lo hacemos afrontando las cuestiones desde una perspectiva feminista. El hecho de plantear temáticas próximas a sus intereses les ayuda a reflexionar sobre problemas que son actuales y que al mismo tiempo mantienen un recorrido histórico, como pueda ser la lucha por los derechos humanos (Krahe, 2017). Algunos conceptos son constantes en el arte de nuestro tiempo y en el de cualquier época: la vida y la muerte, el amor, el odio, el poder, la educación, o el cuerpo. Somos partidarios de revisar lo que ha ocurrido en la historia del arte, comenzando por lo que está ocurriendo en la actualidad, sin perder nunca de vista el papel de las mujeres.

Podemos utilizar dispositivos del campo del arte para pensar la escuela, dialogando en el terreno de las experiencias y de las posibles relaciones entre arte y educación, defendiendo el arte participativo, implicando a muchas personas, conectándolas en redes de mediación cultural, todo ello teniendo en cuenta la lección de Paulo Freire, quien apunta hacia la pedagogía crítica, planteando una ruptura de la jerarquía tradicional entre profesorado y alumnado (Freire, 1998)

\section{Promover el conocimiento del arte hecho por $\mathbf{m u}^{-}$ jeres}

En el panorama internacional ha adquirido una enorme importancia el papel de las mujeres artistas. En mi trabajo docente siempre incorporo el arte hecho 
por mujeres. Reivindico el papel de las mujeres en la creación artística. Si hablamos del cuerpo humano, o de la identidad, podemos empezar con las fotografías de Cindy Sherman, y a partir de aquí recuperar otros artistas anteriores como Rembrandt, Caravaggio, Frida Kahlo, Ribera, Louise Bourgeois o Miguel Ángel. Esto es posible si se trabaja desde los motivos visuales, entendiendo las imágenes como una trayectoria de la mirada. Queremos enlazar las propuestas con los intereses del alumnado, de manera que pueda opinar, participar e introducir ideas propias.

La mayoría de mi alumnado son mujeres. Estamos hablando de maestras, futuras docentes que no se van a dedicar a la producción artística ni al comercio con obras de artistas. Su participación en la creación está lejana al mercado, lo cual no impide que puedan convertir el arte en una herramienta capaz de generar grandes satisfacciones pedagógicas. Les animo constantemente a utilizar las posibilidades del arte como argumento educativo, como fuerza capaz de revolucionar la sociedad, como aliento que inspira los cambios y las mejoras sociales (Huerta, 2016).

Al hablar de arte contemporáneo hablamos de artistas vivos, a quienes podemos conocer personalmente. Si son mujeres artistas, entonces estamos incorporando un rasgo de género que visibiliza dicha realidad. Mis alumnas, futuras maestras, deben conocer a estas mujeres que hacen arte y defienden sus propuestas en las galerías, en los museos y en los espacios comunitarios. Para lograr que conozcan este mundo en clave de género les introduzco en el arte hecho por mujeres y también las invitamos para que nos hablen de su obra.

\section{Una metodología basada en el Trabajo por Proyec- tos}

Fernando Hernández incide en que aprender mediante proyectos de trabajo no es lo mismo que hacer proyectos, asumiendo que "el conocimiento que se requiere para dar sentido al mundo en el que se vive no está organizado por hechos, conceptos, procedimientos y valores fijos y dados, sino que es un proceso cambiante y en construcción", ya que "el conocimiento no se configura como una línea recta, sino que está hecho de historias y visiones sobre los fenómenos, refleja intereses que reafirman y que excluyen", al mismo tiempo que esta metodología supone "acercarse a un tema o a un problema para tratar de desvelar sus enigmas, cuestiones y contradicciones" (Hernández-Hernández, 2000, p. 82). Hernández parte de la idea de generar una conversación cultural, en la que se trata de dar sentido y transferirlo a otras situaciones "en la medida que conecte con las pre- 
guntas que dieron origen a los problemas que abordamos y con los interrogantes que los sujetos se plantean sobre sí mismos y el mundo". Dicha conversación sirve de puente entre las identidades de los aprendices, el entorno de aprendizaje y la conexión que se establece con lo que se aprende. Por eso "aprender es también una práctica emocional, no sólo una cuestión cognitiva y comportamental" (Hernández-Hernández, 2000, p. 80)

Planteamos proyectos abiertos, con títulos sugerentes como "identidades", "el miedo", "el cuerpo", "la ciudad", o "las narrativas". Cada proyecto se inicia revisando la obra de una mujer. Al conocer la obra de estas artistas pasamos a elaborar un discurso propio, tanto artístico como pedagógico. Cuando se plantea el proyecto sobre la temática "El miedo" explicamos la obra de Carmen Calvo, que imprime mucha tensión en sus obras de arte, convirtiendo este taller en un el proyecto de innovación educativa "El miedo, geografías del temor". El tema está poco tratado curricularmente, pero es un aspecto vital que conviene analizar, especialmente cuando forma parte del castigo (Foucault, 1995). El miedo es algo que resulta importante tanto para el alumnado como para el profesorado, ya que construye sensaciones y emociones, estados de ánimo y comportamientos que nos afectan y nos transforman. Los miedos nos afectan a todos, y por ello conviene conversar abiertamente sobre ello, y al mismo tiempo realizar acciones artísticas de talante colaborativo que nos ayuden a comprender los miedos que nos invaden como docentes.

En el caso de la propuesta "El cuerpo" utilizamos la idea del cuerpo como construcción cultural (Butler, 2004). En las escuelas aprendemos a pensar nuestro cuerpo desde lo fisiológico. Se le habla al alumnado de sus cuerpos como si en realidad no estuviesen allí. Lo cierto es que nuestro cuerpo siempre nos acompaña. La represión de carácter religioso, médico o político ha repercutido en una mirada hacia el propio cuerpo llena de prejuicios y tabúes. Es por ello que nos atrevemos a superar las tiranías tradicionales para reivindicar un cuerpo más allá de su función social, rompiendo con las obsesiones por el color de la piel, o por el hecho de ser más altos, bajos, gordos o flacos, feos o guapos, masculinos o femeninos. En la diversidad está la fuente de la riqueza, y el respeto a la diversidad es el primer paso hacia una sociedad más justa y equitativa.

Para hablar sobre los cuerpos diversos utilizamos la obra de la joven artista Anna Ruiz Sospedra, cuyas esculturas nos presentan los cuerpos desde una perspectiva abierta y transgresora. Convertimos el taller del cuerpo en el proyecto de innovación educativa "Cuentas pendientes con nuestros cuerpos". Abordamos la cuestión desde el arte, hablando de la obra de artistas de todas las épocas y estilos (Lord y Meyer, 2013). El cuerpo es nuestra forma primaria de comunicación, con nosotros mismos y con el exterior, nuestra geografía primaria. Nos manifesta- 
mos desde nuestros cuerpos, y esta reflexión va más allá de aquello para lo que nuestros cuerpos "habían sido pensados" por parte de las estructuras sociales y culturales.

\section{Instalaciones artísticas sobre la muerte para for- mar educadores}

Para Juliana Almeida Duarte "el arte contemporáneo tiene como cuestión básica proporcionar una experiencia; las instalaciones y performances lo hacen con claridad y de manera más radical, implicando la participación del cuerpo, del artista y el espectador. El cuerpo implicado nos lleva a reflexionar sobre el conocimiento sensible" (Duarte, 2016, p. 142). Y desde la reflexión sobre el propio cuerpo analizamos cuestiones como los miedos o las prohibiciones sociales, aspectos que resultan cruciales para luchar contra la ignorancia, algo que se puede elaborar como discurso implicando también la tradición literaria (Faúndez y Villa Sánchez, 2019). Este planteamiento de la autora brasileña nos ayuda a reconocer en nuestras experiencias de aula un proceso significativo que pretende implicar al máximo al alumnado universitario, en este caso a los futuros maestros y maestras (Rolling, 2017). No estamos hablando de especialistas en historia del arte ni tampoco de artistas, sino de maestros que utilizan el arte como estrategia educativa (Huerta, 2016). Planteamos un taller en el que van a reflexionar sobre la muerte, y al mismo tiempo van a realizar una instalación artística (Ramon y Alonso-Sanz, 2019). El trabajo se ejecuta en equipo, por grupos de cinco personas. Cada equipo expone su idea. Durante cinco semanas se elabora la propuesta.

En las sesiones de realización del taller se asesora al alumnado en aspectos como la selección de materiales, la unión de elementos constructivos, o bien el juego estético de colores y texturas. Al mismo tiempo se van concretando los aspectos conceptuales de cada obra, elaborando un discurso en imágenes que posteriormente se ha de exponer al público (Raquimán Ortega y Zamorano Sanhueza, 2018). Se les explica que el lugar en el que van a instalar la pieza puede favorecer una serie de lecturas fecundas, para lo que se establece un criterio de situación de las piezas en los espacios de la facultad.

El uso de objetos dentro del lenguaje artístico nos lleva hacia una poética de lo objetual. Este es un mensaje que siempre resulta atractivo para el alumnado. La poética está presente en la mirada que lanzamos hacia los objetos, algo que después se explica a través del lenguaje, tanto verbal como icónico. Un buen ejemplo de ello es la obra de Giorgio Morandi. John Berger lo explica diciendo que los ob- 
jetos que pintó Morandi no se pueden comprar en un mercado callejero. No son objetos. Son lugares (todo tiene su lugar), lugares en donde nacen pequeñas cosas (Berger, 2002). Visto de este modo, los objetos adquieren un carácter conceptual que los convierte en manifestaciones de sentido. Así pues, los objetos representados por Morandi ya no son la pieza en sí, se han convertido en una poética de la relación de dicho objeto con todo aquello que le rodea.

Con cada nuevo proyecto analizamos en clase las formas con que se trata el tema a nivel curricular en las escuelas. Nos damos cuenta de que las miradas hacia la muerte por parte del entorno formal están llenas de prejuicios (Colomo Magaña y Cívico Ariza, 2018). El alumnado realiza instalaciones utilizando elementos de reciclaje y objetos cotidianos. Esculturas, instalaciones y acciones performativas que servirán para transmitir una nueva mirada hacia la muerte. Fomentamos un modelo colaborativo de trabajo en el taller de arte, que permite estimular el consenso y que acentúa las posibilidades expresivas y comunicativas de los futuros docentes (Planella y Esteban Bara, 2018).

\section{Exponer las producciones artísticas en el Museo de Ciencias Naturales}

El hecho de saber que sus producciones serán expuestas en un museo constituye un factor añadido de motivación para el alumnado. Durante la fase de realización del proyecto, la idea de poder enseñar públicamente sus instalaciones incide positivamente en el interés por ser innovadores y atrevidos (Nardi, 2008). Recordamos las palabras de Chiara Panciroli cuando se refiere al museo como entorno privilegiado para la educación, ya que con estos montajes provocamos "Un proceso de recreación poética, un esfuerzo de imaginación combinado con un riguroso conocimiento", lo cual "representa uno de los posibles modos de interpretar la realidad" (Panciroli, 2016).

La ocupación del espacio por parte del alumnado a través de sus instalaciones supone un reto de organización. Al preparar las acciones hay que pedir permiso a la dirección del museo, comprometiéndose a no estropear ninguna instalación, y a dejar posteriormente en perfectas condiciones los entornos utilizados. Este esfuerzo de coordinación supone al mismo tiempo un buen modo de transmitir el respeto hacia los espacios públicos. El efecto sorpresa surge cuando el resto del alumnado comprueba que han sido intervenidos lugares "poco habituales para exposiciones de arte" como puedan ser pasillos, servicios, escaleras o incluso ascensores. Con estas acciones se reivindica un mayor aprovechamiento de los equipamientos, convirtiendo así lugares de paso en entornos artísticos de 
exhibición. El efecto sorpresa es una de las características que mantiene el interés por descubrir alicientes que provocan las instalaciones en lugares estratégicos. Lo que conseguimos con estos "site specific" es generar interés entre el alumnado. La utilización de los espacios es un elemento propio de las "ARTografías" (Irwin y O'Donoghue, 2012).

Tras haber realizado los proyectos comprobamos el buen nivel del trabajo artístico llevado a cabo por los futuros maestros. Mediante instalaciones artísticas reflejan sus temores analizando sus ideas sobre la muerte, generado significados con el uso de objetos cotidianos y de espacios públicos. Se han empoderado de la mirada intensa del arte, $y$ han sabido concretar sus ideas mediante poéticas visuales. Cuando iniciamos la asignatura de Proyectos, les digo que el único que confía en sus posibilidades artísticas soy yo mismo como profesor, ya que el propio alumnado no reconoce sus potenciales, y de hecho desconfía de poder llegar a buenos resultados. A la mayoría siempre les habían dicho que "no eran buenas" para la creación artística. Al terminar sus trabajos comprueban que eran capaces de transmitir sus ideas mediante las artes, a través de instalaciones e intervenciones. Ahora se han empoderado del uso de las artes, y ya son conscientes de sus posibilidades, habiendo superado los miedos iniciales.

\section{El proyecto artístico "La muerte"}

La muerte, un aspecto que no aparece en el currículum de la formación de docentes, es un tema tabú en muchos aspectos. Pero es una cuestión muy tratada por el feminismo en sus diferentes etapas teóricas. Para llevar adelante el proyecto partimos de la obra de la artista francesa Sophie Calle. El alumnado realiza instalaciones artísticas, teniendo en cuenta la posibilidad de incorporar objetos, pinturas, fotografías y demás elementos con los que construir sus obras.

Los dos primeros años de los estudios de Grado de Maestro de Primaria son de ámbito general, pero a partir del tercer año se elige una de las menciones que se ofrecen. En la Mención de "Arte y Humanidades" se ofrece la asignatura optativa cuatrimestral titulada "Propuestas didácticas en educación artística". Los dos grupos suman en total 100 alumnos matriculados en las dos opciones horarias. Soy el profesor de ambos grupos, lo cual permite implicarles en una propuesta que favorece el contacto entre ambos, ya que habitualmente el alumnado de la mañana no suele conocer al alumnado de horario de tardes. En esta ocasión nos hemos aventurado en un proyecto que, además, tenía la posibilidad de exponerse en el Museo de Ciencias Naturales (Huerta y Hernández, 2015).

Los proyectos de trabajo permiten desarrollar un discurso abierto que evo- 
luciona con la participación e implicación de todo el alumnado y el profesorado.

De los cinco proyectos que se proponen durante el tiempo que dura la asignatura, unos individuales y otros en grupo, "La muerte" ocupa cinco semanas de taller, con sesiones que incluyen procesos de discusión y debate, explicaciones o aportaciones diversas, y por supuesto momentos para elaborar las instalaciones. Animamos al alumnado utilizar las posibilidades del arte como argumento educativo, como fuerza capaz de revolucionar la sociedad, como aliento que inspira los cambios y las mejoras sociales (Hernández Belver y Hernández Ullán, 2019). Consideramos primordial aproximarnos a sus realidades y coyunturas sociales, políticas y económicas, evitando así discriminaciones (Alonso-Sanz, 2019b), ya que la "falta de consideración de la herencia cultural familiar incluye la presión que ejerce el propio sistema educativo a través del curriculum escolar oficial, que releva ciertos contenidos y sujetos históricos sobre otros: los que están vinculados esencialmente a los sectores dominantes de nuestra sociedad" (Muñoz et alt., 2013: 137).

La exposición de Sophie Calle en el Musée de la Chasse et la Nature de Paris titulada Beau Doublé, Monsieur le Marquis es un buen ejemplo de lo que intentamos transmitir. Gracias al trabajo realizado por la artista en esta magnífica exposición, el alumnado pudo plantear mejor sus ideas. En Beau Doublé, Monsieur le Marquis rinde homenaje a su padre y a su gato, ambos muertos recientemente. Utiliza el mecanismo de generar arte para superar el duelo de la doble pérdida. Haber podido ver la muestra de Sophie Calle nos facilitó mucho el engranaje de la propuesta. Y aquí enlazamos con otros posibles discursos filosóficos, políticos o culturales, acercándonos a una mayor "conciliación con la naturaleza y sus dos leyes fundamentales: el amor y la muerte, en el propio ritual” (Nitschack, 2016: 164).

\section{Preparando el proyecto en el taller implicando a mujeres artistas}

El alumnado asume que se puede hacer arte con objetos sencillos, realizar una serie de instalaciones artísticas, teniendo en cuenta la posibilidad de incorporar todo tipo de objetos y elementos con los que construir sus instalaciones. Se trata de encontrar la poética del objeto, transitando por la línea de la poesía visual. También intentamos que todo el proyecto se lleve a cabo avanzando desde la perspectiva de la cultura visual. Como indica Pierre Chateau "La estética ha permitido que los artefactos visuales producidos en todo el mundo sean "equivalentes": proceso de normalización, despojador de sentido crítico que no puede 
seguir siendo ignorado" (Chateau, 2017: 23). El taller sirve para que cada equipo construya una instalación artística plasmando sus reflexiones sobre la muerte. Las sesiones de reflexión ocupan la primera parte de la preparación del proyecto (Huerta, 2020). Hablamos sobre la muerte, pero también sobre las necesidades y los intereses del propio alumnado en relación con este tema.

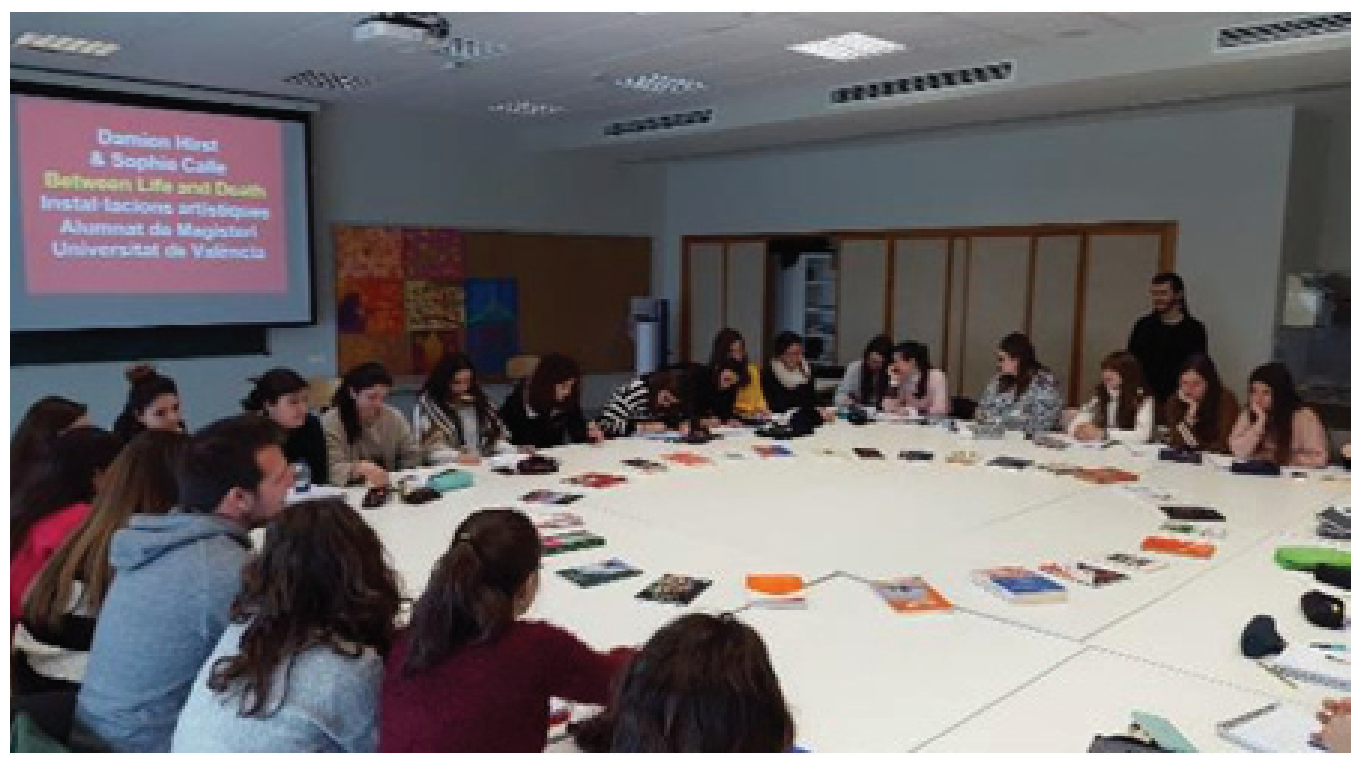

Figura 1. Sesión preparatoria del proyecto "La muerte" en el aula de la facultad.

Un aspecto importante a destacar de la preparación del proyecto son las visitas previas al museo, para conocer los espacios, para conversar con la directora Margarita Belinchón, con la educadora Sandra Illobre, con el alumnado en prácticas y con el personal técnico que nos tenía que asesorar y ayudar al montaje. Son unas visitas muy provechosas, ya que se resuelven las dudas del alumnado para definir dónde ubicarán sus instalaciones. Esta fase de preparación es clave para conseguir la coherencia expositiva que se pretende. La tercera visita al museo ya es con los materiales preparados para montar. De nuevo un esfuerzo de organización para poder atender a los 100 alumnos con sus 18 instalaciones que debían colocarse en diferentes lugares del museo. Los aspectos de coordinación técnica se habían estado preparando anteriormente en el aula, de modo que en un solo día se pudieron montar todas las piezas, algunas de ellas de grandes dimensiones. 


\section{Instalaciones artísticas en el Museo de Ciencias Naturales}

Las instalaciones se sitúan a lo largo del recorrido de la exposición permanente del museo. Se trata de una importante colección de fósiles, ubicados en diferentes salas. Se intenta que las instalaciones generen un ritmo adecuado para que el visitante pueda reconocerlas en medio del resto de piezas y explicaciones del propio museo. La novedad de esta propuesta es que no se trata de una exposición montada en una sala con las piezas del alumnado, sino que las 18 instalaciones se han distribuido por todo el recorrido del museo, de manera que el espectador debe "buscarlas" en cada sala. El efecto sorpresa de este planteamiento le da un aire más lúdico y de descubrimiento a la visita (Alonso-Sanz, 2020).

Las 18 obras del proyecto "La muerte" se expusieron en el Museo de Ciencias Naturales de Valencia durante los meses de abril, mayo y junio de 2018. Las instalaciones transmiten la idea de la muerte representada por el propio alumnado universitario. El buen resultado de las piezas y su repercusión entre el numeroso público asistente nos permite analizar la nueva mirada hacia el arte que ha experimentado el alumnado. La faceta creativa e innovadora del proyecto supone un contacto directo con el museo, uno de los más visitados de la ciudad, y una hibridación desde lo educativo entre los conceptos de "artes visuales" y "ciencias naturales". El Museo de Ciencias Naturales es un lugar que habla sobre la vida a través de vestigios de animales muertos. La exposición "Vivir la muerte" nos ofrece la oportunidad de mostrar al público los trabajos artísticos del alumnado en un entorno patrimonial privilegiado (Fontal y Marín, 2018).

Con la exposición Vivir la muerte se fomenta una curaduría educativa que consiste en convertir el museo en un experimento educativo desde las artes, algo que reivindicamos tanto desde el grupo Creari (Huerta y Alonso-Sanz, 2017) como desde el grupo Esbrina (Hernández-Hernández y Sancho-Gil, 2015). Esto supone al mismo tiempo haber utilizado tanto los recursos de las ARTography (Irwin y O’Donoghue, 2012) como de la Investigación Educativa Basada en las Artes (Arts Based Educational Research). No solamente el profesor asume los roles de artista, investigador y docente durante todo el proceso, sino que además el alumnado se implica, investigando desde su posición como creadores. Defendemos la curaduría educativa (Rogoff, 2008), alentando un modelo de exposiciones en museos que favorece la parte educativa de la propuesta, sin caer en el efecto curricular. Al incitar al alumnado a "apropiarse" del espacio del museo, estamos favoreciendo una relación directa con esta institución, en la que las instalaciones adquieren un nuevo valor. 


\section{Algunos ejemplos de obras de la exposición Vivir la muerte}

La instalación La última mirada, realizada por el grupo Barbara Kruger (Aurora Cartagena, Olga Puig, Sandra Ruiz y Laura Vidal) presenta tres lápidas a tres alturas distintas en la pared. Las lápidas se pueden abrir, ya que disponen de un mecanismo de apertura que maneja el visitante. Cuando se abre la lápida vemos nuestra propia cara reflejada en un espejo. Según explican las alumnas: "Queremos transmitir la imagen de la muerte, a la que todos llegaremos tarde o temprano. A través del espejo te das cuenta de que el próximo puedes ser tú. La idea principal es aceptar la muerte como un proceso cotidiano, y eliminar todo tabú para que reflexionemos y disfrutemos el máximo nuestro día a día." El hecho de verse en un espejo dentro de una tumba impacta de manera insólita al visitante. Las diferentes alturas están pensadas para las diversas medidas del público (desde niños hasta adultos).

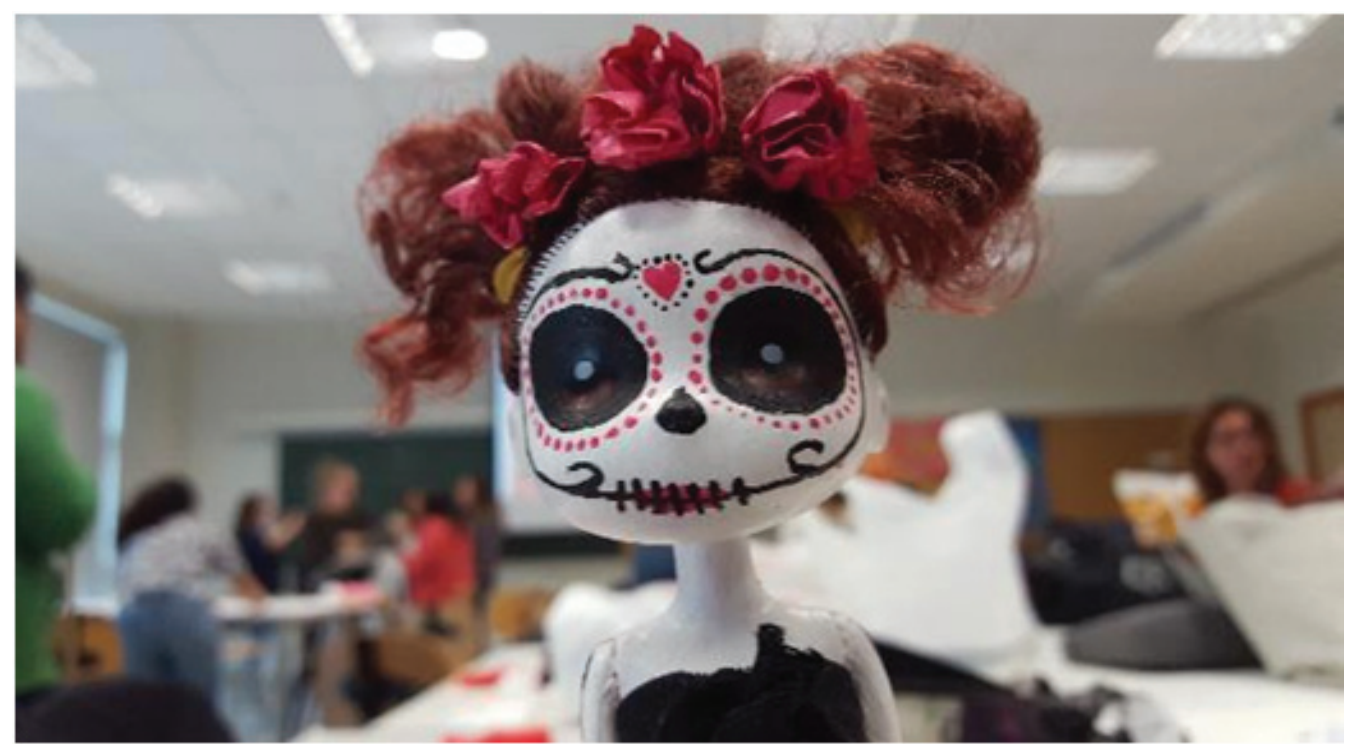

Figura 2. Figura pintada para la instalación Los colores de la muerte.

En el proyecto Los colores de la muerte el duelo en las distintas culturas es representado con diversos colores. Júlia Algarra, Paula Martínez, Héctor Ródenas y María Soler, miembros del grupo Coco Chanel explican que en las culturas occidentales el negro es el color protagonista, mientras que en las culturas orientales el blanco domina como muestra de pureza. Para algunas culturas africanas el rojo 
es el color del paso a otra vida. México es uno de los países donde más vistoso es el culto a la muerte.

La instalación Somos flores y semillas reivindica a los desaparecidos durante la dictadura franquista, miles de personas que fueron fusiladas y que siguen en las fosas comunes de las cunetas de las carreteras donde fueron dejadas, abandonadas. El grupo Frida Kahlo está compuesto por Lourdes García, Paula Gómez, Álvaro Olivares, Maria Ortiz y Mar Pons. La instalación es una réplica de un camino, un recorrido hecho con macetas transparentes en las que hay flores y objetos que recuerdan a los desaparecidos. También han realizado un video muy impresionante que se puede ver en la exposición. Según los alumnos, han querido representar un camino que nos lleva a recordar la injusticia de aquellos desaparecidos durante la dictadura franquista, que sin flores también fueron enterrados. Como si se tratara de una herida abierta, aproximadamente 88.000 personas todavía nos gritan desde las cunetas. La tierra late esperando que los encontremos.

La instalación Comerse la muerte nos habla de la importancia de la comida en los rituales funerarios. Realizada por el grupo Cindy Sherman (Olga Cases, Andrea Canet, Carla Benlloch, Andrea Vidal y Laura Moratalla), plantea que la comida está muy vinculada al momento de la muerte, ya que una costumbre cultural consiste en reunir a los familiares y amistades alrededor de una mesa con comida para recordar y hablar de la persona difunta. Han querido plasmar esta tradición en su proyecto mediante una instalación con una tumba cubierta por un mantel con diferentes tipos de comida a modo de picnic. Por su parte, El árbol de la muerte representa el vínculo entre vida y muerte. El árbol representa la vida en perpetua evolución. De él cuelgan imágenes de retratos de la artista Lita Cabellut (quien da nombre del grupo, formado por Loli Fuentes, Nieves Martínez, Rosa Martínez y Begoña Sáez). Con las hojas caídas del árbol simbolizan el final de la vida. Lita Cabellut pinta retratos a gran escala incorporando técnicas de frescos tradicionales con aplicaciones modernas de pintura al óleo.

Los componentes del grupo Louise Bourgeois, único formado exclusivamente por chicos (Juan Carlos Jordán, Marcos Hidalgo, Adrián González, Honorat Marchuet), presentan el proyecto La muerte de la autosuficiencia. Si bien la mayoría de grupos han trabajado la muerte como un espectro, o algo tangible, ellos deciden hacer algo diferente, en los límites de la ironía, al presentar un proyecto que, pese a estar "hecho" por ellos, no es así en realidad (Ramon, 2020). 


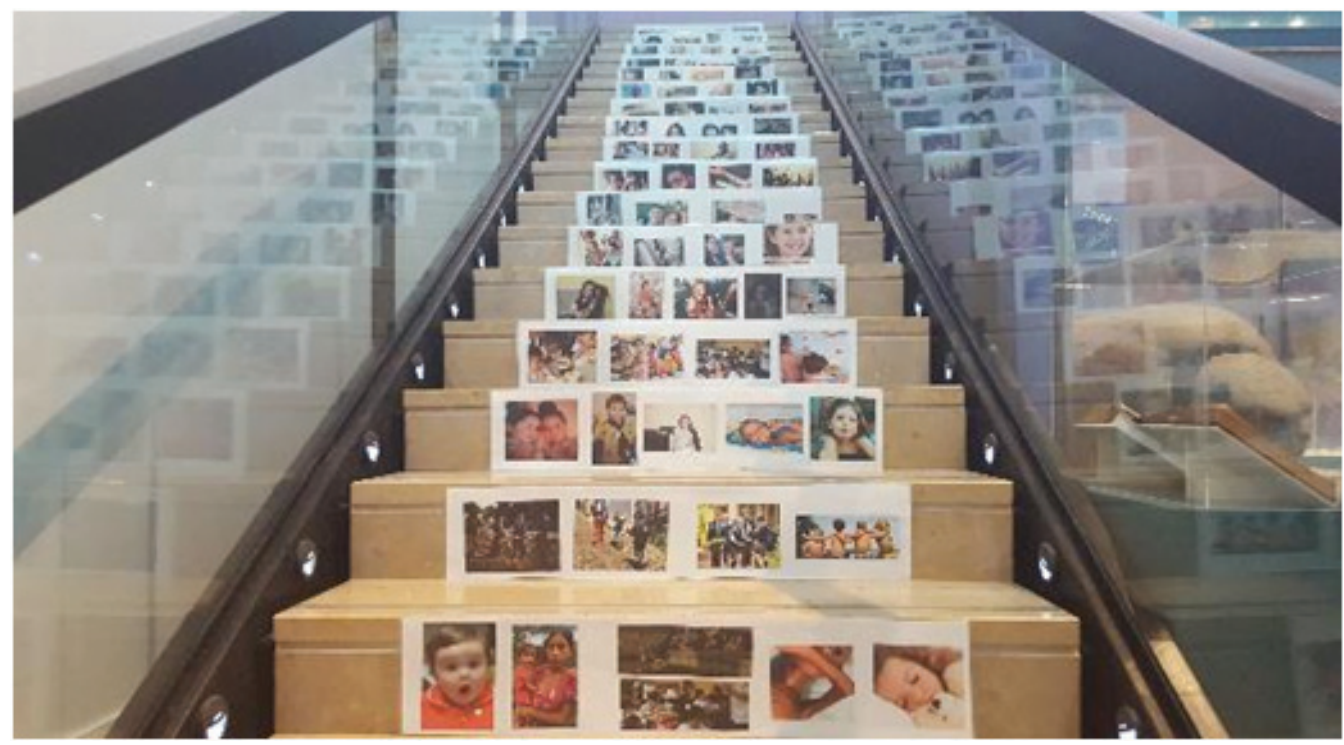

Figura 3. Instalación La escalera de la vida con fotografías en la escalera del museo

Gracias a la instalación La escalera de la vida se planteó en clase una sesión en la que se revisaron numerosas obras de arte de toda la historia en las que se trata las fases de la vida. El trabajo realizado por el grupo Anna Ruiz Sospedra (Isabel Amador, Guillem López, Paloma Ruiz, Javier Santirso y Marta Torró) nos explica que la vida es un compendio de etapas que viajan del nacimiento a la muerte, y todos vamos a transitar por esta senda. Dos elementos opuestos pero necesarios. Con la muerte fluye la vida. Se trata de una instalación muy bien planteada en su ubicación, ya que la sorpresa del espectador surge cuando al bajar las escaleras descubre las imágenes en los escalones. La instalación Enjauladas nos muestra la presión y el abuso que se ejerce sobre los cuerpos de las mujeres. Realizada por el grupo Ana Navarrete (María Ferris, Alba Forner, Alba García y Paula Martínez), simboliza el velatorio en recuerdo de la persona difunta. Con una corona de flores las alumnas quieren representar un aspecto cultural de la muerte. Una jaula le da a la instalación una visión social de la vida, ya que representa la situación en la que se encuentra cualquier persona que vive en sociedad, especialmente si es mujer. Uno de los logros más interesantes del conjunto del proyecto es gran la variedad y riqueza de conceptos y materiales que se han utilizado para las piezas creadas. 


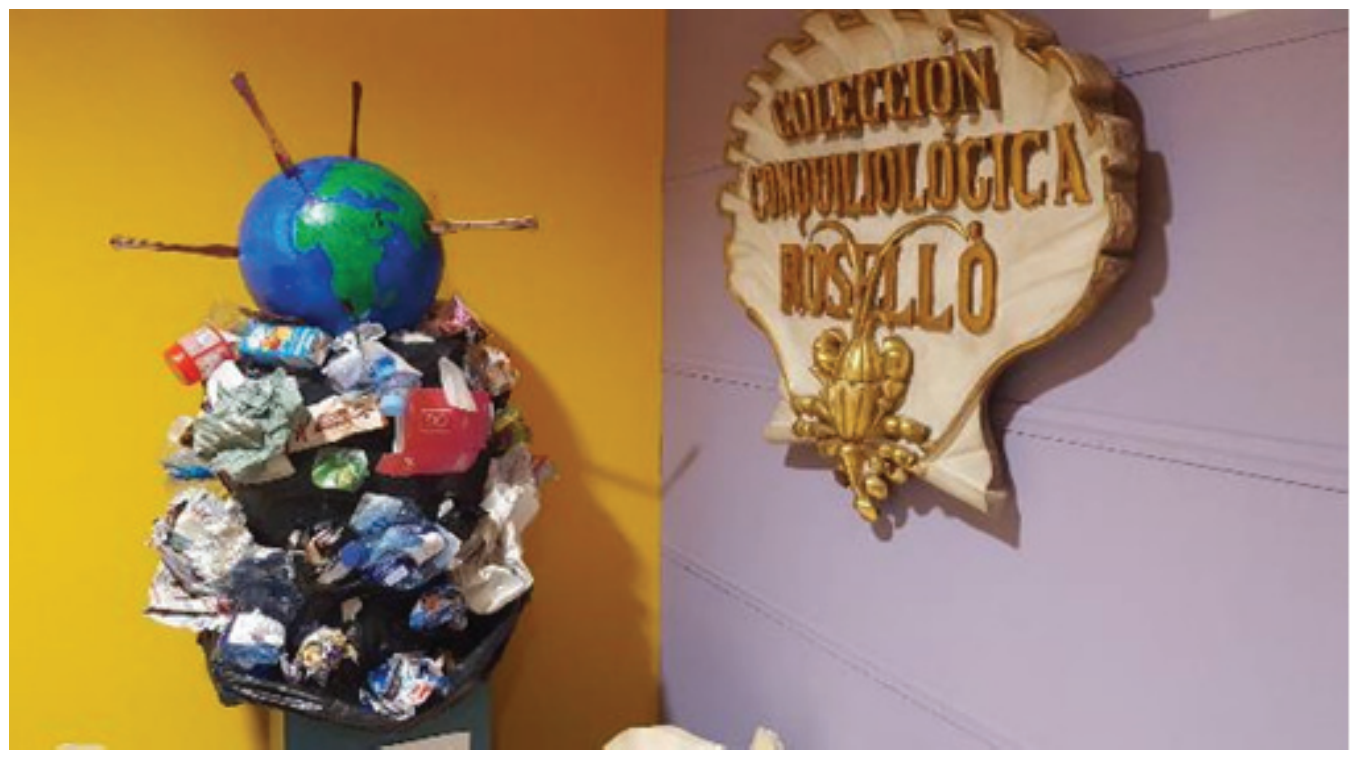

Figura 4. Asesinos del medio ambiente, instalación reivindicativa desde la ecología.

En la instalación Asesinos del medio ambiente quien muere es el planeta, asesinado por la población. El grupo Georgia O'Keeffe, compuesto por Susana Catalá, Dana Hernández, Iris Leone y Carla Rodríguez, pretende mostrar el impacto negativo del ser humano sobre el medio ambiente. Nos recuerdan que somos responsables de la degradación del planeta, pero también quienes podemos salvarlo. Las toneladas y toneladas de basura van acumulándose ¡no dejemos que lo cubra del todo!

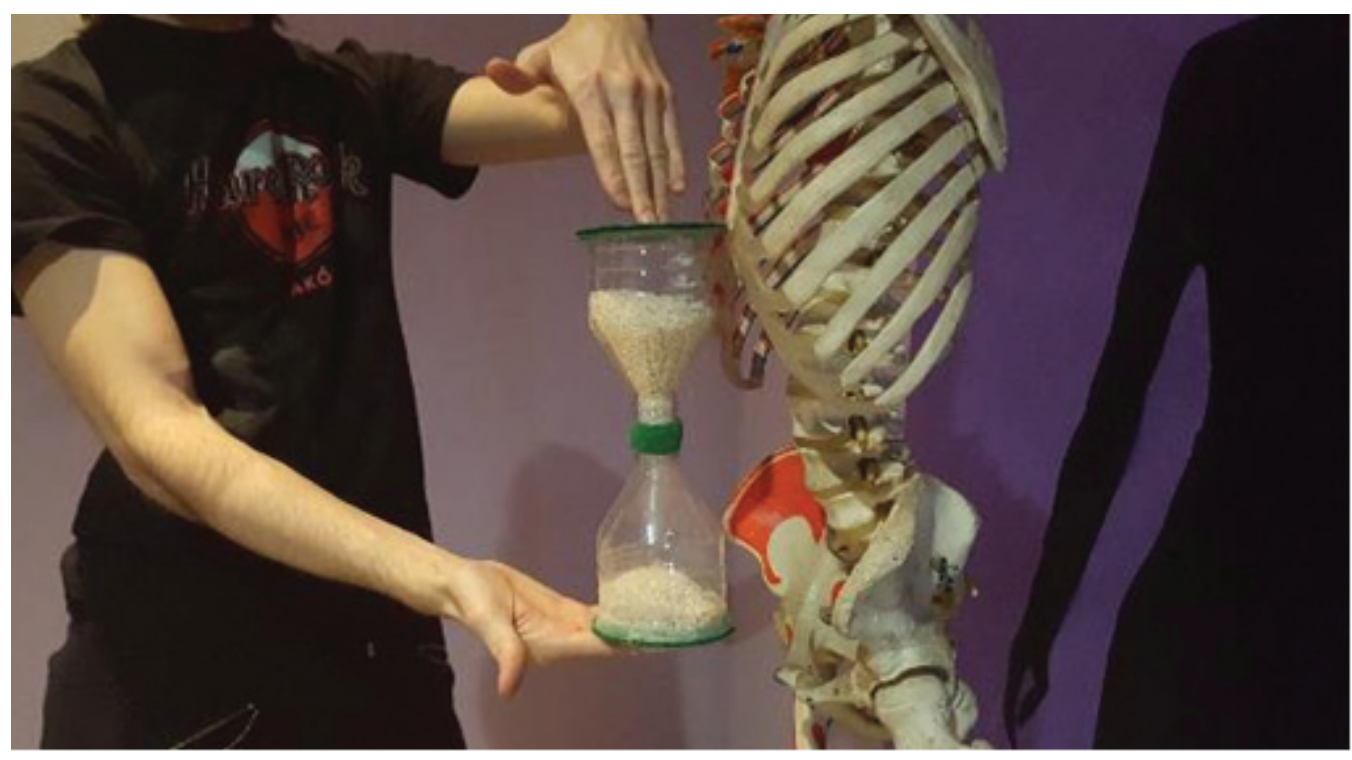

Figura 5. Que se te pasa el arroz, una de las instalaciones del proyecto "La muerte". 
Los miembros del grupo Carmen Calvo (Enrique Miralles, Anna Rubio, Laura Lazcorreta y Borja Gutiérrez) representan de forma cruda y directa lo que consideran una muerte en vida para la mujer, estigmatizada de forma negativa y peyorativa por no querer ser madre a una edad determinada, convirtiéndose en anatema. Un esqueleto y un reloj de arena lleno de arroz, a la altura de la pelvis (zona de los ovarios), rememoran la frase deleznable "se te pasa el arroz", junto a "La guía de la perfecta esposa". Francisco Ahedo, David Argilés, Ana Hernández y Clara Sánchez, miembros del grupo Cinta Tort, presentan el montaje Vanitas: todos sabemos que al transcurrir los años, lo vivo envejece, y la vejez desemboca inevitablemente en la muerte. Ningún recurso es lo bastante eficaz en la lucha contra el paso del tiempo para aquel que desea vivir para siempre. Tarde o temprano, el individuo ha de mirarse al espejo y enfrentarse a la inevitable verdad de que el ciclo de la vida continúa. Nacimos, vivimos, y moriremos.

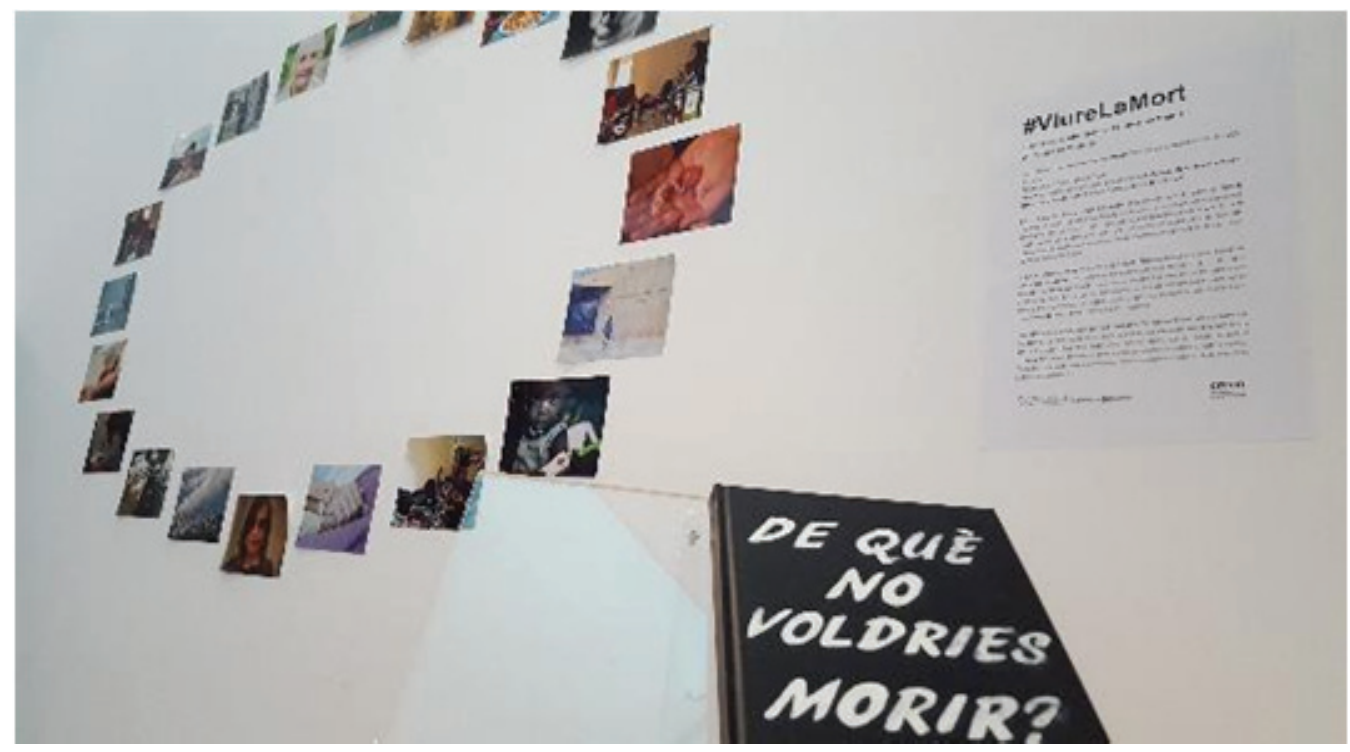

Figura 6. Instalación Entre la luz y la oscuridad con su libro de visitas.

La pieza Entre la luz y la oscuridad representa la muerte a partir de diferentes imágenes, y el transcurso del tiempo mediante un conjunto de huesos. Las componentes del grupo Sophie Calle (Cristina Sapena, Belén Magaña, Reme Roca, Lara Cubillos, Noelia Ruiz) establecen que luz y oscuridad son dos hermanas que juegan con el caos y el orden. La luz juega con el caos dando vida a la muerte, y con el azar, ya que sin saber cómo, cuándo ni dónde, nos convertirnos en polvo para la eternidad. La oscuridad ordena y consume en silencio, sin miramientos ni cuestiones de raza o clase. No hay luz sin oscuridad. El trabajo incluye un Libro de 
visitas en el que la gente puede escribir "de qué no me gustaría morir". La finalidad del proyecto La muerte del amor es hacernos reflexionar sobre el olvido hacia uno mismo y la muerte del propio ser, ya que el amor hacia nosotros mismos es lo que nos mantiene vivos. El grupo Yoko Ono (Nuria Andreu, Irene García, Paula Izquierdo, Nerea Pérez, Laura Rubio) nos cuestiona: ¿Alguna vez has pensado cuánto te quieres y lo que eso influye en ti? Leemos en el proyecto Re-nacer: si hay algo seguro en esta vida, es la muerte. Es un inicio que conlleva un final. El final de cualquier ser vivo y en cualquier circunstancia. Las alumnas del grupo Paula Bonet (Victoria Azorín, Sandra Cerdà, Fernanda Gómez y Tamara Martos) defienden una vida digna para la mujer, ya que el momento del embarazo es el inicio de la vida. Al mismo tiempo, denuncian las muertes injustas, haciendo explícitas las tragedias que suceden a nuestro alrededor.

La primera consecuencia de nacer es morir, nos dicen los autores del proyecto El ciclo de la vida. Un día, de repente, es el último de nuestras vidas. Todos sabemos que ese momento llegará, pero pocos se paran a pensar en ello. Eva Segrelles, Nerea Tatay, Javier Català, Raúl Padial, del grupo Marina Abramovic, piensan en la vida como en una serie de fases que todos experimentamos en el mismo orden hasta llegar a un último estado. Representan este ciclo desde la rama biomédica, balanceándose entre vida y muerte.

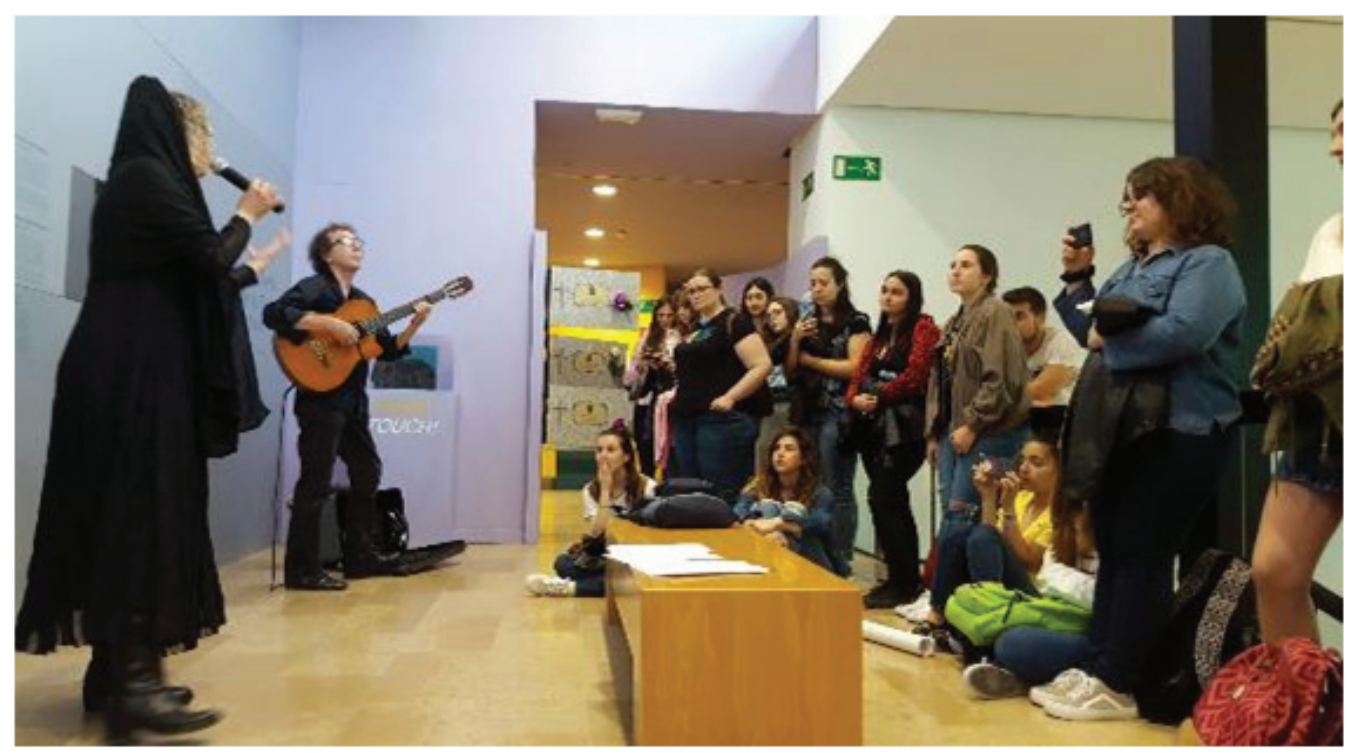

Figura 7. Concierto temático sobre "La muerte" en el Museo de Ciencias Naturales

Como son educadoras en formación, y no artistas o historiadoras, su mirada nos acerca a los intereses docentes. Se trata de potenciar el valor del patri- 
monio que les pertenece, agitando así sus conciencias y posibilitando que reflexionen sobre sus propios intereses. Para poner un broche final a la experiencia, el Museo de Ciencias Naturales organizó un concierto temático sobre "La muerte", con canciones de diferentes épocas, que transcurrió a lo largo del recorrido de la exposición, con una canción interpretada ante cada obra.

Para desarrollar la experiencia y difundirla en redes se ha utilizado el hashtag \#VivirLaMuerte, dando a conocer la muestra mediante imágenes, animando al público a hacerse selfies delante de las piezas y a enviar sus mensajes a través de las redes. Este contacto con las tecnologías permite publicitar la exposición, al tiempo que se consigue que la gente hable de un tema tabú como es la muerte. El 18 de mayo de 2018, para celebrar el Día Mundial de los Museos, con el lema "Museos Hiperconectados, Nuevos Enfoques, Nuevos Públicos", el Ayuntamiento de Valencia propuso al alumnado hablar público asistente, planteando conexiones entre universidad y ayuntamiento (las instituciones más importantes de la ciudad), arte y ciencia, educación y arte contemporáneo, contrastando el tema de la muerte con el arte y la educación, y combinando la producción artística con la recepción científica. Se habló con públicos de todas las edades, conectando al alumnado con los usuarios tanto en directo como mediante el hashtag \#VivirLaMuerte.

\section{Conclusiones}

Desde hace unos años planteamos proyectos basados en temáticas poco frecuentes en la formación de educadores, como puedan ser "El miedo", "El cuerpo", "La memoria", "La diversidad" o "La muerte". Estas acciones siempre se vinculan a mujeres artistas en activo, lo cual repercute en el conocimiento del trabajo de las mujeres creadoras por parte del alumnado de Magisterio, reforzando así la mirada hacia los feminismos desde las artes y la educación. Artistas mujeres están colaborando con nosotros para llevar adelante estas propuestas que incorporan el arte contemporáneo a las prácticas de formación de educadores, propuestas que llevamos a cabo en la universidad pública y que fomentan la integración. La metodología utilizada parte de la investigación-acción en educación, incorporando elementos que proceden de las Artography y también de la Investigación Educativa Basada en las Artes.

Las instalaciones nos hablan de expectativas, de intereses, de deseos, de saberes, todo ello desde las poéticas de la expresividad. Han trabajado en equipo y por tanto han sido capaces de colaborar para realizar una pieza artística. El espíritu de cooperación ha estado presente en toda la evolución del proyecto, ya que 
se han aportado ideas, se han contrastado opiniones, y finalmente se han tomado decisiones conjuntas. Tras haber realizado este taller comprobamos el buen nivel del trabajo artístico llevado a cabo por los futuros maestros y maestras. La primera barrera que hay que salvar es la poca confianza inicial del alumnado en sus capacidades creativas. Al terminar sus trabajos comprueban que eran capaces de transmitir sus ideas mediante instalaciones e intervenciones performativas. Ahora son conscientes de sus posibilidades. Cada año, con cada nuevo grupo de clase, recupero la confianza en el trabajo docente y en la capacidad del alumnado para enfrentarse al lenguaje artístico. De este modo, cada curso volvemos a superar los miedos iniciales, ya que el alumnado se enfrenta a los prejuicios que tenía sobre el potencial educativo de las poéticas del arte. Con estos proyectos se consigue transitar por una serie de etapas de preparación y ejecución, se elaboran ideas y se realizan instalaciones artísticas, incorporando la exposición en el museo como elemento potenciador de interés. Resulta fundamental contar con el apoyo de artistas para llevar adelante una educación artística basada en las emociones y en las buenas prácticas.

\section{Referencias}

Abad Faciolince, H. (2010). El olvido que seremos. Barcelona: Seix Barral.

Alonso-Sanz, A. (2019a). Actitudes de docentes y discentes ante la otra: la madre universitaria. REIRE Revista d'Innovació i Recerca en Educació, 12(1), 1-14.

Alonso-Sanz, A. (2019b). Estilo de gestión femenina: estudio de caso de las mujeres Bunker. Communiars, 2, 31-56.

Alonso-Sanz, A. (2020). Una profesora flâneuse en París. Cartografías en la formación inicial de docentes. Arte, Individuo y Sociedad, 32(2), 363-386. DOI: https://dx.doi.org/10.5209/aris.63670

Berger, J. (2002). The Shape of a Pocket. London: Bloomsbury.

Butler, J. (2004). Undoing Gender. New York: Routledge.

Duarte, J. (2016). Saber sensível para a educação: como a mediação cultural em Arte Contemporânea pode atuar na sala de aula, Revista Matéria-Prima, 4(3), 139-146.

Chateau, P. (2017). Cultura visual e Historia del Arte. La puesta en evidencia de los Estudios Visuales, Universum, 32(2). 15-28. DOI: http://dx.doi.org/10.4067/ 
Colomo Magaña, E. y Cívico Ariza, A. (2018). La necesidad de formación del profesorado en pedagogía de la muerte. Revista Electrónica Interuniversitaria de Formación del Profesorado, 21(1), 83-94. DOI: http://dx.doi.org/10.6018/reifop.21.1.279961

Faúndez, E. y Villa Sánchez , G. (2019). Cinco representaciones del sujeto homosexual en la narrativa hispanoamericana (1895-1938), Universum, 34(1), 95-118. DOI: http://dx.doi.org/10.4067/S0718-23762019000100095

Fontal-Merillas, O. - Marín-Cepeda, S. (2018). Patrimonio inclusivo: hacia un índice para la evaluación de la inclusión educativa al patrimonio, Cadmo. Giornale Italiano di Pedagogia Sperimentale. An International Journal of Educational Research, XXVI (1), pp. 7-24. DOI: https://doi.org/10.3280/CAD2018-001003

Foucault, M. (1995). Discipline and Punish: The Birth of the Prison. New York: Vintage Books.

Freire, P. (1998). Pedagogy of Freedom. Maryland: Rowman y Littlefield.

Hernández Belver, M. y Hernández Ullán, C. (2019). From Velázquez to Picasso: Proposal of Artistic Mediation Activities for People with Dementia. Barcelona, Research, Art, Creation, 7(1), 10-29. DOI: http://dx.doi.org/10.17583/brac.2019.3820

Hernández-Hernández, F. (2000). Los proyectos de trabajo. Mapa para navegantes en mares de incertidumbre. Cuadernos de Pedagogía, 310, 78-82.

Hernández-Hernández, F. y Sancho-Gil, J. M. (2015). A learning process within an education research group: an approach to learning qualitative research methods, International Journal of Social Research Methodology, 18(6), 651-667. DOI: https://doi.org/10.1080/13645579.2015.1049468

Hamlin, J. y Fusaro, J. (2018). Contemporary Strategies for Creative and Critical Teaching in the 21st Century", Art Education, 71(2), 8-15.

Huerta, R. (2016). Art Education for Social Change: Human Rights and Sexual Diversity, en Eça y others (eds.) Risks and Opportunities for Visual Arts Education in Europe, Porto, APECV / InSEA, pp. 46-50.

Huerta, R. (2020). Arte, género y diseño en educación digital. València: Tirant lo Blanch.

Huerta, R. y Alonso-Sanz, A. (2017). Entornos informales para educar en artes. 
València: PUV.

Huerta, R. y Hernández, A. (2015). Educación artística y gestión de museos: intereses y expectativas del alumnado a partir de encuestas manuscritas. Cadmo. Giornale Italiano di Pedagogia Sperimentale. An International Journal of Educational Research, 23(2), 47-64. DOI: https://doi.org/10.3280/CAD2015-002006

Irwin, R. y O'Donoghue, D. (2012). Encountering pedagogy through relational art practices, International Journal of Art y Design Education, 31(3), 221-236.

Krahe, A. M. (2017). Arts Equity: A Praxis-Oriented Tale, Studies in Art Education A Journal of Issues and Research, 58(4), 267-278. DOI: https://doi.org/10.1080/00 393541.2017 .1368293

Lord, C. y Meyer, R. (2013). Art y Queer Culture. Londres: Phaidon.

Muñoz, C., Ajagan, L., Saéz, G., Cea, R. y Luengo, H. (2013). Relaciones dialécticas antagónicas entre la cultura escolar y la cultura familiar de niños y niñas de contextos vulnerables, Universum, 28(1), 129-148. DOI: http://dx.doi.org/10.4067/ S0718-23762013000100007

Nardi, E. (2008). Educazione e mediazione nei musei, Cadmo. Giornale Italiano di Pedagogia sperimentale. An International Journal of Educational Research, 16(2), $1-6$.

Nitschack, H. (2016). Antropofagia cultural y tecnología, Universum, 31(2), 157171. DOI: http://dx.doi.org/10.4067/S0718-23762016000200010

Panciroli, Ch. (2016). Los bienes culturales como patrimonio educativo, EARI Educación Artística Revista de Investigación, 7, 86-99.

Planella, J. y Esteban Bara, F. (2018). Aspectos que valdría la pena recuperar para la educación universitaria de hoy, Cadmo. Giornale Italiano di Pedagogia Sperimentale. An International Journal of Educational Research, 26(1), 25-36. DOI: https://doi.org/10.3280/CAD2018-001004

Ramon, R. (2020). Interseccions entre imatge, art i tecnologia per a la construcció de coneixements sensibles. Temps d'Educació, 58, 121-134. DOI: https://doi. org/10.1344/TE2020.58.10

Ramon, R. y Alonso-Sanz, A. (2019). La deriva paralela pedagógica. Un hilo educativo invisible entre Porto y Paris a través de narrativas personales. Revista Portuguesa de Educação, 32(2), 74-90. DOI: https://doi.org/10.21814/rpe.17200 
Raquimán Ortega, P. y Zamorano Sanhueza, M. (2018). Historias de vida profesional y prácticas pedagógicas en la enseñanza de las artes visuales, una mirada reflexiva, Cartema, 7, 16-23.

Rogoff, I. (2008). Turning, e-flux Journal, \#00, 32-46.

Rolling, J. H. (2017). Art + Design Practice as Global Positioning System, Art Education, 70(6), 4-6. 